\title{
MIAZMA: \\ PHYSICS EDUTAINMENT THROUGH A COMPUTER GAME
}

I Zs. Fülöp, S. Biri and G. Lévai - MTA Atomki, Debrecen, Hungary - DOI: https://doi.org/10.1051/epn/2017508

The beginning of the $21^{\text {st }}$ century is characterised by several contradictions and challenges. One of them is that scientific and technological development has never been as important for the well-being of humankind as today. Nevertheless, these fields seem to lose the attention of talented and interested youngsters. 


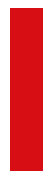
$t$ is thus in the interest of all of us in science to demonstrate the beauties of scientific research to the young generation. The classical methods do not seem to be sufficient to complete this task, so new, innovative techniques have to be developed to capture the attention of the teenage generation.

The Miazma project was inspired by these ideas. Furthermore, the course of events outlined above is especially regrettable in Hungary, a country where physics and natural sciences in general, have always been highly valued. This is the reason why a group of physicists at the Institute for Nuclear Research, Hungarian Academy of Sciences (MTA Atomki), Debrecen [1] decided to address high school age students directly, through their preferred medium, a computer adventure game. It was a

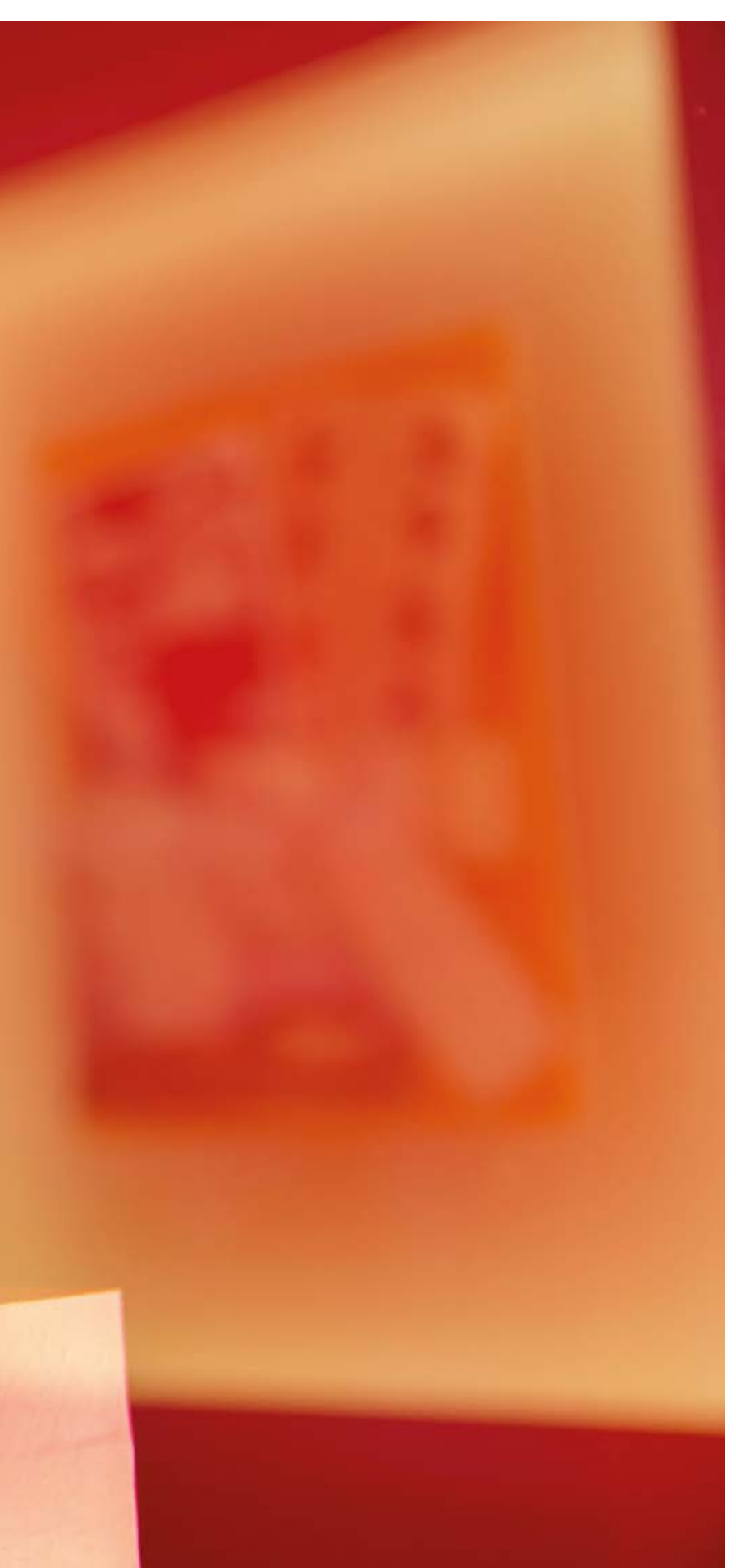

long time ago, around the dawn of the personal computer era, when the present authors were in the age group of the targeted audience, so finding the right language with the latter was a real challenge. In order to facilitate the inter-generation communication, young colleagues, practicing high school teachers, as well as junior family members were asked to contribute to the efforts. The key partner, however, was a professional company, Private Moon Studios, that had extensive experience in developing computer-based adventure games, as well as tabletop and conventional strategic board games [2]. The director of this company was also a popular singer-songwriter performing under the name Pierrot, and this fact in itself helped to abolish the generation barrier to the target audience.

Needless to say, scientists and artists contemplated each other with some reservation during the early stage of the project. The two groups couldn't have differed more in their socialization, cultural background and in general, in the way they looked at the world. We, scientists, tried to resolve this shock jokingly, recalling stories from the time of the Manhattan Project, when two utterly different communities had to work jointly to reach a common aim. Nevertheless, it soon turned out that there are many common features in the thinking of scientists and artists, and that the differences also served as the source of mutual inspiration for the two groups in overcoming difficulties. In the end we all agreed that both science and developing adventure games can be considered as special forms of problem solving.

The story of Miazma [3] takes place in the present, but refers back to several historical moments from the past few hundred years. It contains both fictitious and realistic elements. Fictitious are all the characters appearing in the game in the present. However, the key characters of the past, István Hatvani, the professor of the Reformed College of Debrecen from the $18^{\text {th }}$ century, and Sándor Szalay, the founding director of Atomki are real. The meteorite that landed at Kaba, near Debrecen in 1857 is also real, while the other meteorites playing role in the story are fictitious.

From the technical point of view, Miazma is an interactive film in the style of the "third person point-and-click" adventure PC Windows games. In other words, it is built of short film scenes embedded in an interactive computer game environment. Real locations are covered by live-action cinematic approach, while the narrative depends on the actions of the players themselves. Their decisions open many possible alternative routes, all from a single starting point towards one fixed ending. Besides the film and the story, puzzles provide the main motivation for players. In Miazma there are more than 30 puzzles, at varying levels of difficulty. Most of the
4. 42: The fictitious meteorite on exhibition in the AGORA Science Centre, Debrecen 
> FIG. 1: Jonathan and the head of the Radiocarbon Laboratory, with her beloved plants and animals. This

laboratory is marked by green colour in the game to help the orientation.

puzzles incorporate scientific problems (fictitiously) created by Prof. Szalay several decades ago. According to the story, these problems were designed to be solvable only in a later age (the present), when the necessary technology would become available. With this, Prof. Szalay wanted to hide potentially dangerous objects in his time, and guarantee that they would be handled by trustable individuals scientists of the $21^{\text {st }}$ century. In working out the details we tried to keep scientific rigour at a sufficiently high level. However, compromise was made at several instances in order to make the storyline more fluent.

In the starting scene, a journalist, Jonathan Hunt arrives at Atomki, where he meets a young physicist, Vera. In her office the player can practice the controls of the game (selecting objects, using the inventory etc.). Jonathan's visit soon turns into an investigation for a missing teenage boy Balázs, Vera’s younger brother. The characters of Jonathan (who already appeared in other adventure games) and Balázs represent the experienced detective and the curious teenager, whom the players can identify with during the game.

Edutainment: The process of entertaining people at the same time as you are teaching them something, and the products, such as television programmes or software, that do this. (Cambridge Business English Dictionary, Cambridge University Press)

Miasma: A vaporous exhalation formerly believed to cause disease. (Merriam-Webster Dictionary)

Miazma: A new edutainment PC computer game developed in MTA Atomki, Debrecen, Hungary.
Jonathan starts the investigation by visiting the laboratories of the institute. For a better identification, each laboratory has a specific colour and decoration (see Fig. 1.). Furthermore, each scientist has some hobby, which also turns out to be useful in solving the puzzles. The following laboratories are shown and visited (some named slightly differently in the game):

- Surface Science Laboratory

- Ion beam Analysis Laboratory

- Computer Centre

- Cyclotron Control Room

- Plasma Physics Laboratory

- Radiochemistry Laboratory

- Radiocarbon Laboratory

During this stage Jonathan (and the player) gets the first impressions of the activities of the laboratories and the technologies available there.

The investigation also extends beyond the gates of the institute to the city of Debrecen, revealing some of its rich cultural heritage. It is at the visit to the Reformed College [6] when a meteorite first comes into the picture (Fig. 2.). Further pieces of information about the missing boy are collected in the College library, in an old church and in an observatory.

Meanwhile, the boy tries to escape from an underground labyrinth of cellars (Fig. 3). From this point, the storyline is temporarily no longer linear; we can follow both his escape and the investigation. In the labyrinth, common tools are to be combined and used with the laws of physics to open the next door and move on. These cover standard high-school physics topics, including mechanics, thermodynamics, electricity etc. A booklet is at hand to help the player, written in the style of the 1960's, in the form of a dialogue between a father and his 10-year-old son, on everyday aspects of physics. 
Finally, Jonathan's investigation reveals a secret safe in the director's office, well hidden by Professor Szalay decades before (Fig. 4). He obviously wanted to leave important messages to posterity. There are six combination locks on the safe, and a small chest with six corresponding compartments, each containing "coded messages". Using these messages (usually a set of small objects or enigmatic notes), Hunt relies on the assistance by the laboratories again in finding the combinations for the locks. From this point, the player can proceed in any order, visiting any of the labs or returning anywhere later. Solving the puzzles often requires objects or information obtained at another location earlier. The six puzzles are based on the following objects and physical methods:

1. Lapis lazuli in small bottles: element analysis and date labelling

2. Rubber bell and a bone flute: sound frequency calculation and measurement

3. Old gold-plated coin: multiple thin layers, depth analysis

4. Picture of a rainbow: plasmas from noble gases, wave lengths

5. Lead box with radioactivity sign on it: irradiation with cyclotron beam, PET camera study

6. A ring and a clock face: the Szalay-Csikai neutrino experiment in 1956 [4]

With the help of the scientists, Jonathan Hunt (and the player) figures out the next step needed to proceed with the puzzles. In this scientific investigation he uses the instruments, methods and knowledge de facto available in Atomki.

Finally all the puzzles are solved and the safe opens! Of course we cannot reveal what is found there and what is the end of the story. Instead, we encourage the readers to play the game and enjoy the thrill of science and adventure.

The game is a result of the long-term evolution of Atomki's outreach activities and its collaboration with high school teachers of the city. The Hungarian version of Miazma was a standalone project co-financed by the European Social Fund (grant agreement no. TÁMOP-4.2.3-12/1/KONV-2012-0057) and distributed in DVD format to the readers of a major science magazine in Hungary, available in all high school libraries. Recently, we have provided free download of the game for the entire Hungarian community. The Agora Science Centre of Debrecen [7] visited by thousands per year provides a special exhibition space for Miazma, where visitors can not only play the game, but also see the mysterious meteorite and the safe as well. The scene in which Balázs escapes from the labyrinth was also reconstructed temporarily for a science summer school, where many visiting students had the opportunity to test their skills in a realistic situation.
The Reformed College of Debrecen, founded in 1538, has always been the symbol of the Calvinist tradition of Debrecen. The college played a major role in the cultural and religious life of Hungary for centuries. Many famous Hungarian writers, poets, as well as scientists studied there. The college had strong links with universities in Switzerland, Germany and Holland: numerous graduates of the college visited these institutes, and on returning home, promoted the modern ideas learned there. The rich collection of the College Library also dates back to the time of these "peregrines", whose donations were essential in enlarging it. One of the most renowned professors of the College was István Hatvani (1718-1786), who studied mathematics, physics and medicine in Basel, Utrecht and Leiden. He refused the invitation for professorship in Leiden, and returned to Debrecen to become professor of the Reformed College. He had an extensive teaching activity, but he was most renowned for his experiments with electricity, earning him the title "Hungarian Faustus".

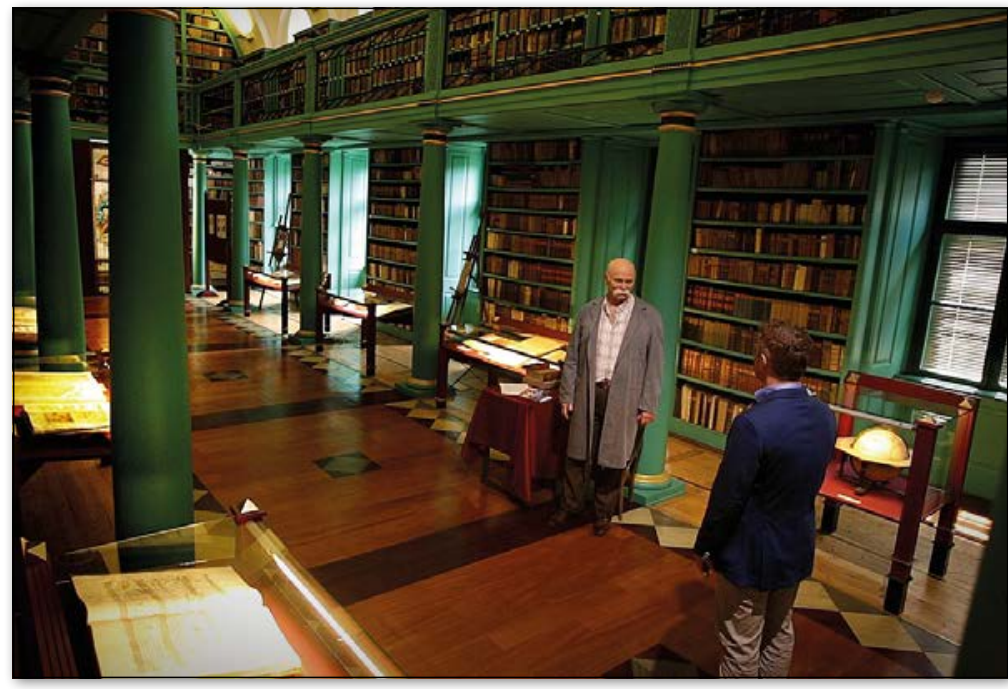

$\Delta$ FIG. 2: Collecting information in the library of the Reformed College.

Founded in 1954, the Institute for Nuclear Research (MTA Atomki) belongs to the network of research laboratories administered by the Hungarian Academy of Sciences. The founding director Sándor (Alexander) Szalay (1909-1987) studied nuclear physics in Cavendish Laboratory, Cambridge, where he worked with Nobel Laureate Lord Ernest Rutherford. In 1956, together with his Ph.D. student, J. Csikai, he performed a cloud chamber experiment that indirectly proved the existence of (anti)neutrino in the beta-decay of ${ }^{6} \mathrm{He}$. For this achievement Atomki was declared EPS Historic Site in 2013 [4]. Atomki has developed into a national accelerator centre, where about 110 researchers work in nuclear, atomic and particle physics, as well as in environmental science. The present research policy of Atomki follows the interdisciplinary approach always characterizing the institute [5]. 


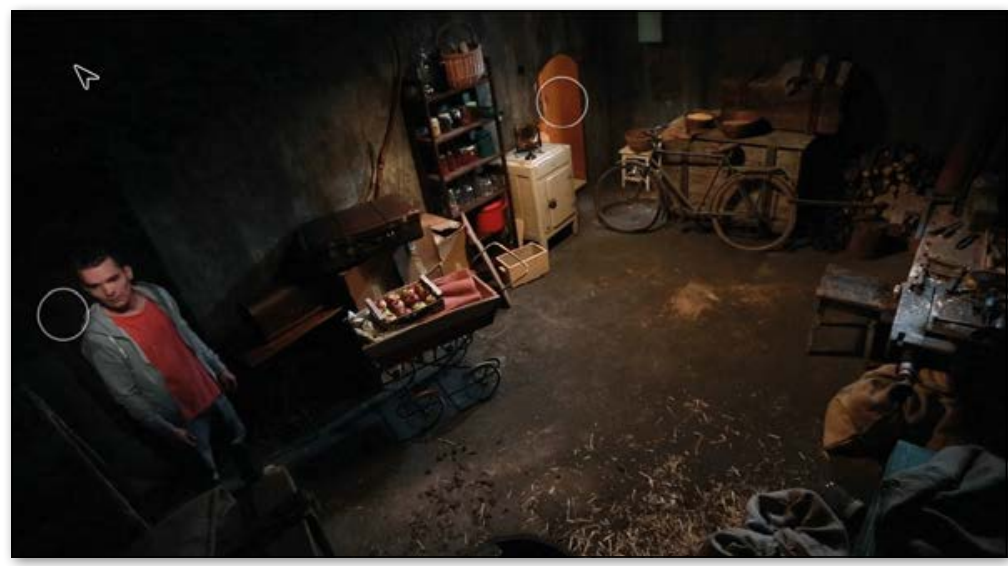

The international version was presented first at the $10^{\text {th }}$ edition of the Science on Stage Festival in Debrecen, 2017 attended by more than 400 science teachers from all over Europe [8]. The international version of the game, however, is not public domain. It can be downloaded from the Atomki web page [9] and limited number of activation codes can be requested from the sponsors of the game: the European Physical Society [10], the Nuclear Physics European Collaboration Committee (NuPECC) [11] and the ENSAR2 European project [12] through the European Union's Horizon 2020 research and innovation programme under grant agreement No 654002. Negotiations are under way with major gaming download sites, e.g. STEAM, to make the game available on the European market.

As an epilogue, one may wonder whether one can really learn physics from adventure game based on a science related story. Maybe not. However, and this is the firm belief of the authors, it can help to feel the thrill of scientific investigation, to appreciate the power of hightech instruments and, eventually, to understand the importance of evidence based research.

\section{About the Authors}

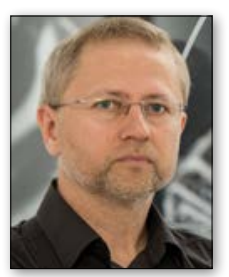

Zsolt Fülöp is scientific adviser at MTA Atomki working in the field of nuclear astrophysics. Former chair of the EPS Nuclear Physics Division and former member of the EPS Executive Committee.

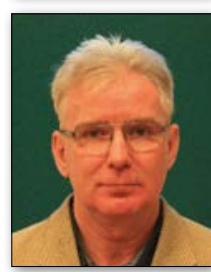

Sándor Biri is senior researcher at MTA Atomki. His research interest is atomic plasmas, ion sources and accelerators R/D. He is presently the head of the Accelerator Center of Atomki.

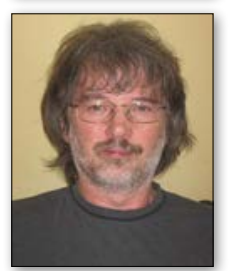

Géza Lévai is scientific adviser at MTA Atomki. His field of interest is symmetry-related studies in quantum mechanics and theoretical nuclear physics. Presently he is the deputy director of Atomki.

\section{References}

[1] www.atomki.hu/en/

[2] http://gamedev.privatemoon.com/en

[3] https://youtu.be/ItF3kHGO5MY

[4] R. G. Lovas, Europhysics News 45/1, 04 (2014)

[5] Zs. Fülöp and G. Lévai, Nuclear Physics News 25/4, 05 (2015)

[6] https://en.wikipedia.org/wiki/Debrecen_Reformed Theological_University

[7] http://www.agoradebrecen.hu/en/

$\triangle$ FIG.3: Escaping from the underground labyrinth.

[8] http://sons2017.eu/

[9] www.atomki.hu/miazmaeng

[10] http://www.eps.org/

V FIG. 4: The hidden [11] http://www.nupecc.org/

safe with six

combination locks. [12] http://www.ensarfp7.eu/

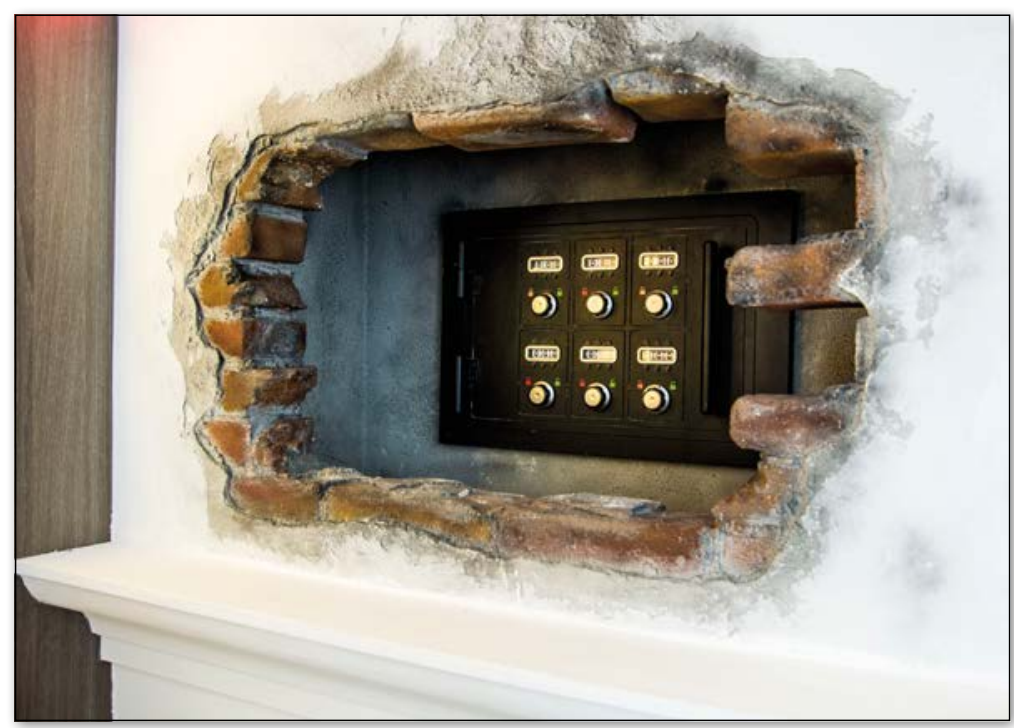

Private Moon Studios [2] is an independent Hungarian game developer company specialized in computer games, board games and touristic games. They developed a range of interactive city adventure games, offering an opportunity to learn about the historic sights of a city in the course of an exciting investigation. The first interactive movie game of the company was Yoomurjak's Ring, the first in the line of Jonathan Hunt Adventures. The game's deep storyline has been subsequently extended into a novel. The protagonist, Jonathan Hunt is a young journalist from New York who has Hungarian ancestry. His first trip to Hungary begins as innocently as a vacation in the city of Eger, but soon turns into a treasure hunt for a mysterious ring and hidden messages from the past. The game features real-life locations to be discovered virtually and an immense amount of movie footage, pictures and panoramic photos. 